\title{
EDITORIAL
}

\section{Forty five years of international journal of fracture}

\author{
Krishnaswamy Ravi-Chandar
}

Published online: 2 November 2010

(C) Springer Science+Business Media B.V. 2010

The International Journal of Fracture has completed 45 years of publication. Transition to the electronic age is now mature; all aspects of the process-from submission to typesetting to publication to archival storageare now handled digital form. Backfiles have been converted to electronic form, and high quality pdf files of all papers published in the Journal over the last 45 years are now available online.

In keeping up with advances in electronic publishing, the Journal is pleased to launch an Electronic Supplementary Materials segment to articles published in the Journal. Such supplementary materials could include data archives, high resolution photographs, videos or animation, computer code segments, or other materials that enhance the quality and utility of the published article. These materials will be permanently archived, hyperlinked to the journal article, and available through the Journal portal. Copyright agreements associated with the print and electronic versions of the main article will also apply to the Supplementary
Materials associated with the article. In addition, the Journal is also pleased to offer free color printing for all art work in the journal. Authors are encouraged to exploit these features and make illustrations visually appealing and technically more accessible to the audience.

The Journal maintains its high standards through its review process; over the past 5 years, about 15 percent of submissions were rejected after editorial review and another 30 percent were rejected after peer review. For the accepted articles, the average time from submission to acceptance stands at about 110 days; accepted articles appear online within a few weeks in a citable format.

I welcome your comments, criticisms and suggestions regarding the Journal so that we can continue to provide an appropriate forum for intellectual exchange on all aspects of fracture. 